\title{
Transgenic Dissection of HIV Genes Involved in Lymphoid Depletion
}

\author{
Brad T. Tinkle, ${ }^{*}$ Hiroyuki Ueda, ${ }^{*}$ Lien Ngo, ${ }^{*}$ Paul A. Luciw, ${ }^{\ddagger}$ Karen Shaw, ${ }^{\ddagger}$ Craig A. Rosen, ${ }^{\S}$ and Gilbert Jay* \\ $*$ Department of Virology, Jerome H. Holland Laboratory, Rockville, Maryland 20855; ${ }^{\ddagger}$ Department of Medical Pathology, University of \\ California, Davis, California 95616; and ${ }^{\S}$ Human Genome Sciences, Inc., Rockville, Maryland 20850
}

\begin{abstract}
Transgenic mice carrying an HIV provirus, with selective deletion of all three structural genes, developed extensive lymphoid depletion which was detected not only in the spleen and lymph nodes but also in the thymus. Mice with a high level of HIV gene expression developed acute disease which resulted in premature death, and mice with a low level of viral transcripts developed chronic disease with longterm survival. Neither HIV replication nor the envelope glycoprotein (gp120) was required for T cell depletion. Despite abundant viral gene expression early in life, cell death did not become evident until about the time of full lymphoid maturation, suggesting that thymopoiesis was not affected. The more mature $\mathrm{T}$ cells in the peripheral lymphoid organs and in the thymic medulla were less sensitive to the apoptotic process than the immature $T$ cells in the thymic cortex. Gradual depletion of the $T$ cell compartment in the peripheral lymphoid organs was intimately accompanied by the reciprocal expansion of the $B$ cell compartment, resulting in the almost complete replacement of $T$ lymphocytes with B immunoblasts in lymph nodes. Unlike $\mathrm{T}$ cells, which showed abundant HIV gene expression, $B$ cells did not. The transgenic approach may help identify the HIV nonstructural gene(s) responsible for immune deficiency and help facilitate dissection of its role in inducing apoptosis. (J. Clin. Invest. 1997. 100:32-39.) Key words: transgenic mice • HIV genes $\bullet \mathrm{T}$ cell depletion $\cdot \mathrm{B}$ cell expansion $\bullet$ apoptosis
\end{abstract}

\section{Introduction}

The hallmark of HIV-1 infection is the dysfunction and eventual depletion of CD4 ${ }^{+}$T cells (1-4). Functional loss of this cell subset affects both the humoral and cellular responses, and results in a variety of immunological abnormalities and opportunistic infections. There is conflicting evidence as to whether HIV-1 infection of CD4 ${ }^{+} \mathrm{T}$ cells is directly involved in their depletion (5-9). Many questions relating to the rapid turnover of $\mathrm{CD}^{+} \mathrm{T}$ cells remain poorly understood. What are the events which occur within infected lymphoid organs where most $\mathrm{CD}^{+} \mathrm{T}$ cells mature and function? Do the $\mathrm{CD}^{+} \mathrm{T}$ cells die as a consequence of HIV-1 gene expression? Are specific HIV-1 genes responsible for functional depletion of $\mathrm{T}$ cells?

Address correspondence to Dr. Gilbert Jay, Department of Virology, Jerome H. Holland Laboratory, 15601 Crabbs Branch Way, Rockville, MD 20855. Phone: 301-738-0801; FAX: 301-738-0410.

Received for publication 31 October 1996 and accepted in revised form 1 April 1997.

J. Clin. Invest.

(C) The American Society for Clinical Investigation, Inc.

0021-9738/97/07/0032/08 \$2.00

Volume 100, Number 1, July 1997, 32-39
How do the HIV-1 genes cause the cell to die? Are cells at a particular differentiation state more susceptible to killing? What are the immediate and long-term consequences of loss of $\mathrm{CD}^{+}{ }^{+} \mathrm{T}$ cells? Are these consequences the same irrespective of whether it is an acute or chronic infection?

To better understand HIV pathogenesis, we introduced a modified form of the HIV-1 genome into the germline of mice. In doing so, we bypassed the infection process and allowed detection of the consequences of viral gene expression in all permissive target tissues. Apart from the structural genes, gag, pol, and env, the HIV-1 genome contains at least six other genes (10). Many of these accessory genes are suspected to play crucial roles in interacting with the host cell to facilitate the viral life cycle (11). To reduce the complexity of the system, we chose to eliminate HIV replication, which is known to generate variants with different pathogenicities, by deriving mice with a replication-defective HIV genome. By doing so, we hope to reduce a moving target to a fixed one and to eliminate the need to deal with the potential host immune response to the free virus. Essentially, this will allow us to concentrate only on the consequences of viral gene expression on the infected cell.

\section{Methods}

Transgenic mice. The HIV transgenic mice were generated by microinjection of a 3.2-kb fragment into single-cell embryos derived from inbred FVB/N mice. Mice from two independently derived transgenic lines were used in this study.

Histological analysis. Mice were anesthetized with metofane and transcardially perfused with $4 \%$ paraformaldehyde prepared in phosphate-buffered saline. Tissues dissected from perfused mice were then postfixed overnight in $4 \%$ paraformaldehyde. Sections of paraffin-embedded tissues were cut at 5- $\mu \mathrm{m}$ thickness and stained with hematoxylin and eosin $(\mathrm{H} \& \mathrm{E})^{1}$ for routine histological analysis.

Immunohistochemical staining. For immunostaining, sections of paraffin-embedded tissue samples were mounted on silane-coated slides, dewaxed, rehydrated, and treated with $0.1 \%$ trypsin for $15-30$ min at room temperature. Sections were incubated overnight at $4^{\circ} \mathrm{C}$ with the appropriate antibody. All immunostained sections were developed with diaminobenzidine substrate using the avidin-biotin horseradish peroxidase system (Vector Laboratories Inc., Burlingame, CA).

Reverse transcriptase-polymerase chain reaction (RT-PCR). $100 \mathrm{ng}$ of DNase-treated RNA prepared from various tissues was reverse transcribed, and amplified using specific primers against tat (5'TGGAAGCATCCAGGAAGTCAGCCTA and 5'CCTGAGGAGCTCTTCGTCGCTG), rev (5'GCGACGAAGAGCTCCTCAGGACAG and 5'CTCTCAAGCGGCGGTAGCTGAAGAGG), and $\beta$-actin (5'CAGGTCATCACCATTGGCAATGAG and 5'CAGCACTGTTGGCGTACAGGTC).

TUNEL assay. Paraffin sections were dewaxed, rehydrated, and digested with proteinase $\mathrm{K}(20 \mu \mathrm{g} / \mathrm{ml})$. Sections were labeled at $37^{\circ} \mathrm{C}$

1. Abbreviations used in this paper: $\mathrm{H} \& \mathrm{E}$, hematoxylin and eosin; RT-PCR, reverse transcriptase-PCR; TUNEL, terminal deoxynucleotide transferase-mediated dUTP biotin nick-end labeling. 
for $60 \mathrm{~min}$ with $\mathrm{TdT}(0.3 \mathrm{U} / \mu \mathrm{l})$ in a cocktail consisting of $25 \mathrm{mM}$ Tris, $\mathrm{pH} 6.6,200 \mathrm{mM}$ potassium cacodylate, $1 \mathrm{mM} \mathrm{CoCl}_{2}, 0.25 \mathrm{mg} / \mathrm{ml}$ BSA, and $2 \mu \mathrm{M}$ biotin-16-dUTP. Sections were then incubated with avidin and biotinylated horseradish peroxidase, and stained with diaminobenzidine.

\section{Results}

The proviral DNA that was injected into single-cell embryos to generate transgenic mice was derived from HIV-1 strain SF2 (12) and contains two internal deletions (Fig. 1). One deletion is located between nt 311 and 4454, and effectively eliminates both the gag and the pol coding sequences but does not affect either the common splice donor site at nt 290 or any of the splice acceptor sites for the nonstructural genes (13). The other deletion precisely removes the intron located between nt 5601 and 7930, and eliminates much of the env coding sequence but conserves all of the open reading frames for the nonstructural genes except $v p u$. Since both the $5^{\prime}$ and the $3^{\prime}$ LTRs are intact, transcriptional initiation and termination are not expected to be affected. With the AUG codons of the Gag, Pol, and Env proteins absent from this construct, no structural proteins or subregions of them can be produced. While $\mathrm{Vpu}$ is missing, the functions of the other accessory proteins in the control of either viral gene expression or gene function in the expressing cells should remain unaffected.

Multiple transgenic mouse lines were derived and two were selected to be expanded for detailed analysis. These two lines were chosen because they have the highest yet very different levels of viral gene expression; the Q5 transgenic line has about a 10-fold higher level of HIV transcripts than the N4 line when tail RNA were compared by Northern blot hybridization analysis (Fig. 2). The RNA species detected range in size from $\sim 1.5$ to $2.5 \mathrm{~kb}$, as predicted from the defective viral genome that was introduced into the germline of these mice. By RTPCR analysis, both the Q5 and N4 mice showed accumulation of viral mRNA in all tissues tested (Fig. 3). These findings sug-
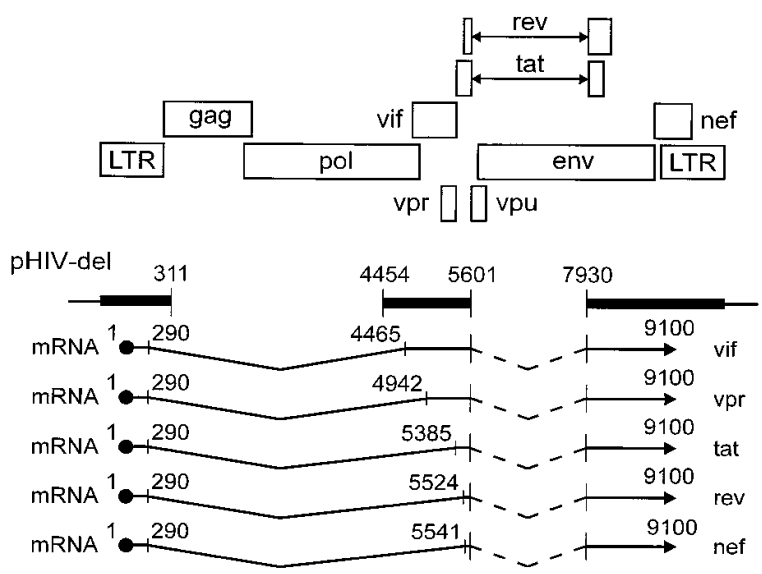

Figure 1. Schematic of the replication-defective HIV provirus used for producing transgenic mice. The pHIV-del construct contains two deletions, located between nt 311-4454 and nt 5601-7930. This modified provirus is shown colinear with the $5^{\prime}$ and $3^{\prime}$ LTRs, as well as open reading frames (top). Also shown are predicted mRNAs for each viral gene encoded by pHIV-del (bottom). Positions of splice junctions for each transcript are indicated. Nucleotide numbers are from the sequence of HIV-1 SF2 by Sanchez-Pescador et al. (47).

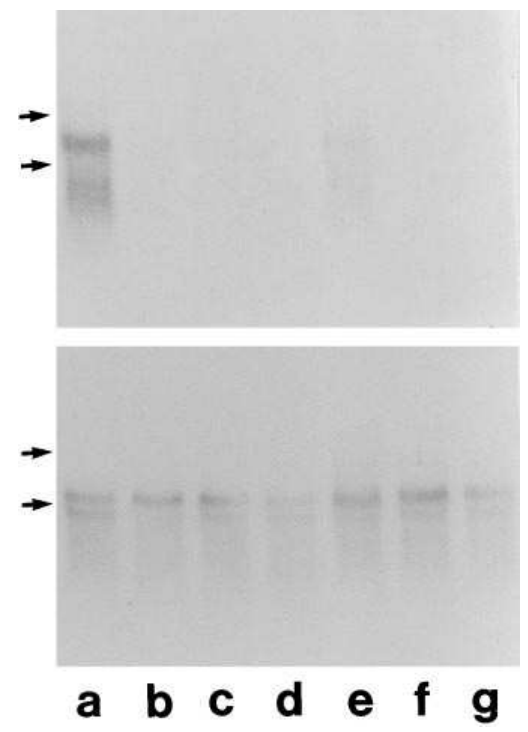

Figure 2. Detection of HIV transcripts in different transgenic mouse strains. Northern blot hybridization analysis was carried out using poly $(\mathrm{A})^{+}$RNA from the tails of independent transgenic lines. The RNA blot was first hybridized to a ${ }^{32} \mathrm{P}$-labeled HIV probe (top) to detect the viral transcripts, before being stripped and rehybridized to a ${ }^{32} \mathrm{P}$-labeled $\beta$-actin probe (bottom) which detects both nonmuscle and muscle actin. The transgenic mouse lines tested include Q5 (a), L3 (b), L8 (c), H4 (d), N4 (e), Q4 $(f)$ and S4 $(g)$. The autoradiograms were underexposed to allow visualization of discrete RNA species, and comparison between the Q5 and the N4 lines. The arrows indicate the positions of 28S and $18 \mathrm{~S}$ rRNA.

gest that HIV gene expression is promiscuous in the mouse. Significantly, despite the widespread expression of viral sequences in these transgenic mice, pathological changes were reproducibly detected in only a small subset of tissues, which includes the lymphoid, renal, and vascular tissues. The severity of changes (lymphoid depletion, glomerulosclerosis, and arteriopathy) correlates closely with the level of viral RNA expression in independent transgenic lines.

The high-expressing Q5 mice developed profound lym-

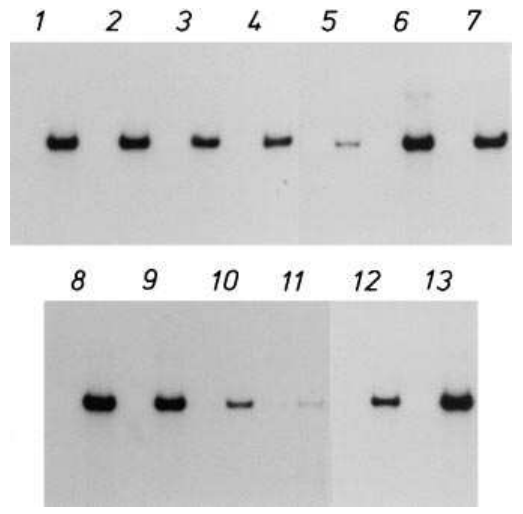

Figure 3. Expression of HIV transcripts in different transgenic mouse tissues. Equivalent amounts of total RNA, extracted from various tissues of a 3-wk-old Q5 transgenic mouse, were amplified by RT-PCR. For amplification a pair of oligonucleotide primers, derived from the second coding exon of rev, was used. This region is

present in every transcript predicted for pHIV-del and is used to determine total HIV gene expression in each tissue. Analysis was performed using three concentrations of each RNA to ensure that RT-PCR signals are within the linear range and that semiquantitative comparisons between different RNA samples may be made. Results from one representative RNA concentration are shown. Tissues analyzed include: (1) spleen; (2) salivary gland; (3) brain; (4) liver; (5) pancreas; (6) kidney; (7) uterus; (8) small intestine; (9) large intestine; (10) heart; (11) skin; (12) muscle; (13) lung. Each RT-PCR reaction was performed either with reverse transcriptase (right lane) or without it (left lane). 

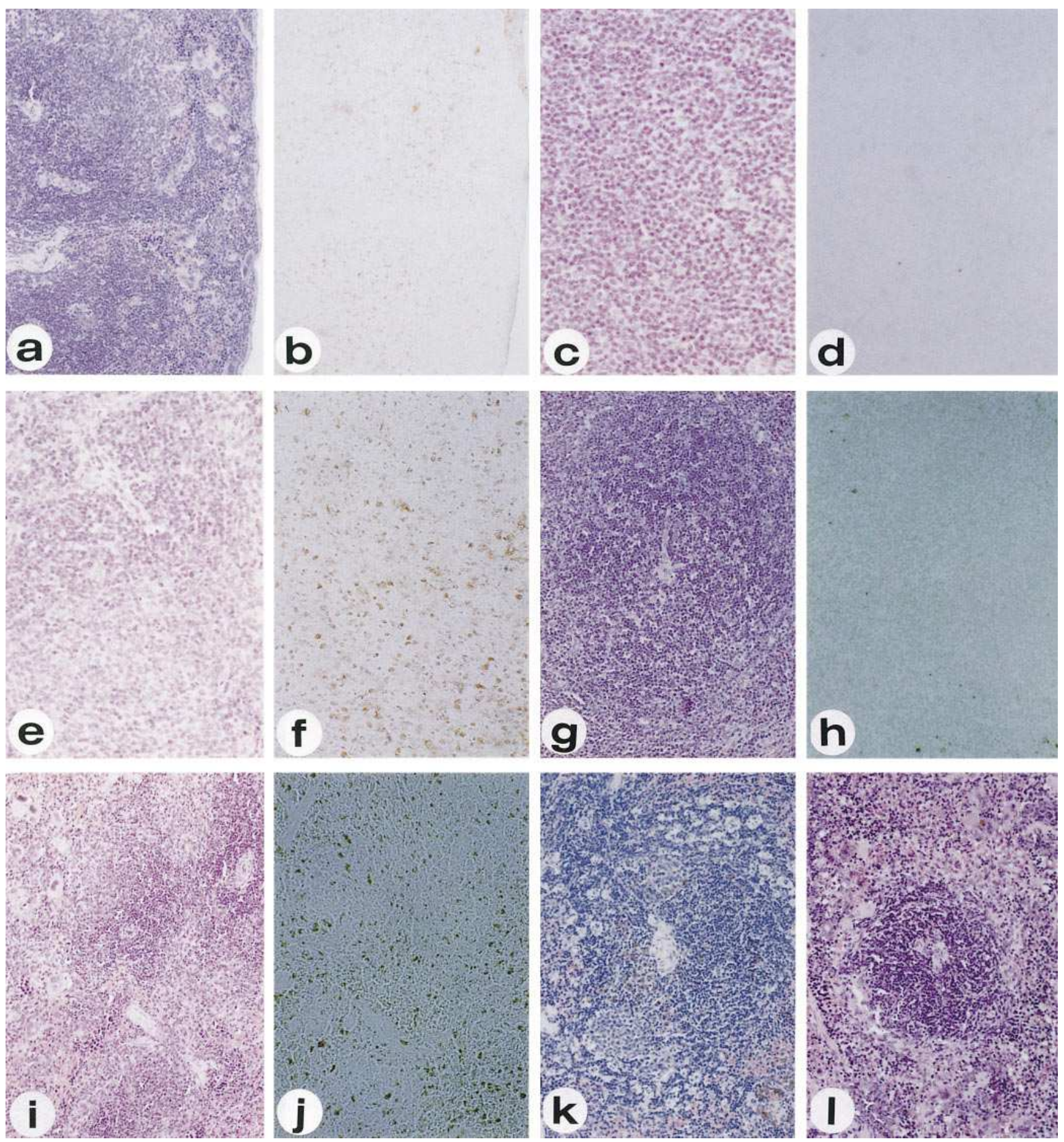

Figure 4. Histopathological changes in the transgenic spleen. (a) Low magnification view of H\&E-stained section of a Q5 transgenic spleen to show the overall splenic architecture $(\times 10)$. (b) Serial section of $a$ immunostained with anti-Rev to display regional specificity in HIV gene expression $(\times 10)$. (c) High magnification view of H\&E-stained section of the T-cell zone within the white pulp of a nontransgenic spleen exhibiting homogeneity of cells $(\times 50)$. $(d)$ Serial section of $c$ immunostained with anti-Rev to show no nonspecific reactivity $(\times 50)$. $(e)$ High magnification view of H\&E-stained section of the white pulp of a Q5 transgenic littermate, showing regional heterogeneity in cellular morphology $(\times 50)$. $(f)$ Serial section of $e$ stained with anti-Rev to demonstrate regional differences in immunoreactivity $(\times 50)$. $(g) \mathrm{H} \& \mathrm{E}$-stained section of a nontransgenic spleen to show the size and cellularity of a normal white pulp $(\times 20)$. $(h)$ Serial section of $g$ stained by TUNEL to demonstrate the absence of apoptotic cells except for an occasional lymphocyte in the red pulp $(\times 20)$. (i) H\&E-stained section of the spleen of a Q5 transgenic littermate to show the extent of depletion and the size of the residual white pulp $(\times 20)$. ( $j$ ) Serial section of $i$ stained by TUNEL to reveal the widespread distribution of apoptotic cells $(\times 20)$. $(k) \mathrm{H} \& \mathrm{E}$-stained section of a N4 transgenic spleen, showing abundant cell death in the outside marginal zone and numerous apoptotic bodies within tingible-body macrophages. $(l) \mathrm{H} \& \mathrm{E}$-stained section of another N4 transgenic spleen, showing complete depletion of the outer marginal zone and presence of numerous pyknotic nuclei in the region immediately around the central arteriole. 

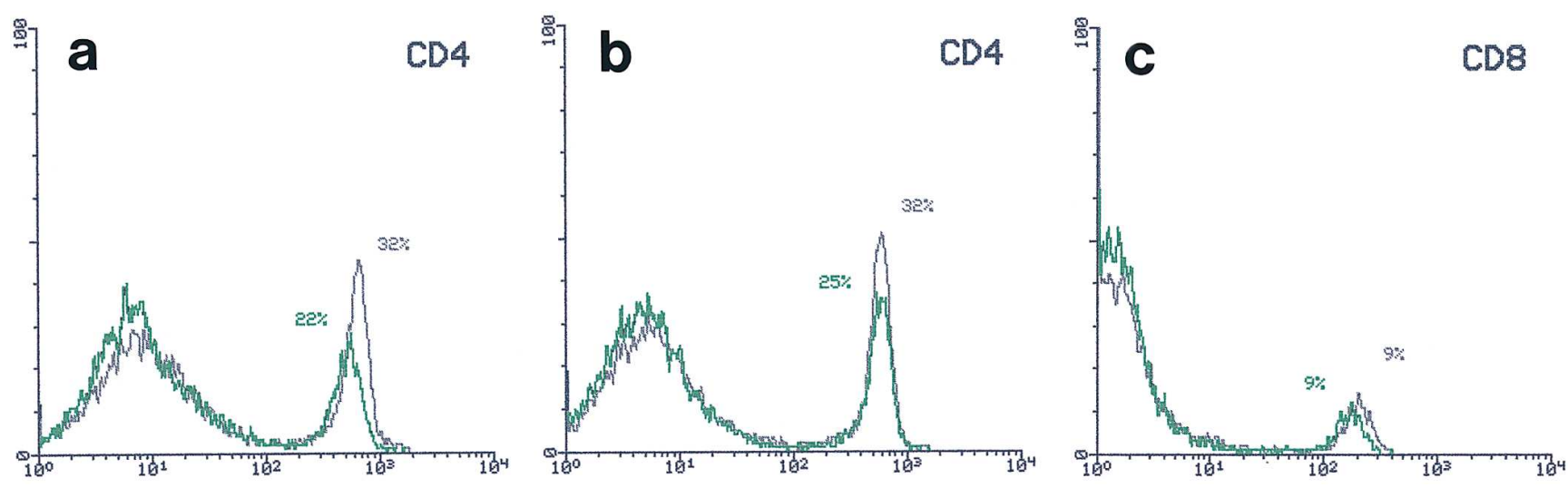

Figure 5. Selective CD4+ T-cell depletion in the transgenic spleen. Splenocytes from individual Q5 transgenic mice, killed at $26 \mathrm{~d}$ of age and before they showed any sign of weight loss, were compared to splenocytes from individual nontransgenic littermates by cytofluorometric analysis using an antibody directed against CD4. With mice from one litter, the percentage of CD4 ${ }^{+}$T-cells dropped from 32 to $22 \%$ when the nontransgenic mouse and its transgenic littermate were compared $(a)$. With mice from another litter, the percentage dropped from $32 \%$ for the nontransgenic mouse to $25 \%$ for the transgenic littermate $(b)$. When an antibody directed against CD8 was used on the same pair of mice shown in $b$, no detectable difference between the nontransgenic mouse and its transgenic littermate was observed $(c)$.

phoid depletion while the low-expressing N4 mice showed similar but less severe lymphoid changes. It appears that Q5 mice manifest acute and $\mathrm{N} 4$ mice manifest chronic immunopathology. All of the Q5 mice from the $F_{1}$ generation which were allowed to mature became moribund at $\sim 5$ wk of age. When compared to their nontransgenic littermates, Q5 mice appeared perfectly healthy and showed normal weight gain up to $\sim 4$ wk of age, when they showed a precipitous weight loss and subsequently died. The Q5 founder mouse was able to survive because she was mosaic, with an estimated one of four cells being transgenic. Since she was fertile, she was able to transmit the transgene to progeny mice but succumbed after multiple breedings. At the time of death, she had lymphoid changes similar to those detected in her offspring. This contrasts with the N4 mice which were both viable and fertile, but many died with lymphoid changes characteristic of the Q5 mice. These results demonstrate that both transgenic lines showed similar pathological changes but with different severity, as described below.

Histopathological analysis of the spleen of a 26-d-old Q5 transgenic mouse, just before its transgenic littermates began to develop signs of cachexia, showed normal overall cellularity with fairly intact white pulp (Fig. 4a). However, unlike its nontransgenic littermate, whose white pulp was made up of darkly stained lymphocytes detected at high magnification (Fig. 4c), those in the Q5 mouse were somewhat heterogeneous and contained regions of palely stained lymphocytes abutting regions of more normal appearing cells (Fig. $4 e$ ). The presence of lymphocytes with a more open nuclear morphology is accompanied by the detection of occasional pyknotic cells which is suggestive of increased cell death within the T-cell areas.

That these changes might have resulted from expression of HIV genes in the transgenic spleen is supported by immunohistochemical staining of a serial section with an antibody directed against the HIV-1 Rev protein. Our choice of using antiRev to demonstrate HIV gene expression was not because we feel that Rev may be involved in inducing lymphoid changes in these mice, but because this antibody is well-characterized and has a proven specificity (14). Immunostaining was detected in specific regions within the spleen (Fig. $4 b$ ), indicative of both antibody specificity and selective HIV gene expression. Although the $\mathrm{T}$ cell area from a nontransgenic littermate had no immunoreactivity with anti-Rev (Fig. $4 d$ ), a similar area from a young Q5 mouse displayed abundant immunostaining, particularly in cells with altered nuclear morphology (Fig. 4f). Interestingly, even within areas with abundant immunostaining, not every cell showed anti-Rev immunoreactivity. This suggests that HIV gene expression is permissive only in T cells at specific differentiation states and causes morphological changes in these cells.

Functional consequences in the spleen at this early stage were analyzed by cytofluorometric analysis of $\mathrm{CD}^{+}$and $\mathrm{CD}^{+}$cells in transgenic and nontransgenic littermates. In each analysis, the transgenic animal exhibited a decrease in CD4 cells when compared to its nontransgenic littermate (Fig. $5, a$ and $b$ ). The CD8 count, however, was not different between the mice (Fig. $5 c$ ). This selective depletion of CD4 cells was not only significant but reproducible, even at a stage when the histopathology was not particularly abnormal.

Many of the Q5 mice from different litters were allowed to mature and every one of them became moribund at $\sim 5 \mathrm{wk}$ of age. At this stage, histological examination of spleens invariably demonstrated extensive lymphoid depletion; white pulp was much smaller in surface area, suggestive of a reduction in total cell number. When compared to the nontransgenic littermate (Fig. $4 \mathrm{~g}$ ), T-cell areas within the white pulp of the transgenic spleen were almost devoid of lymphocytes and many of the remaining cells displayed a pyknotic morphology (Fig. $4 i$ ). Detection of apoptotic cells using the terminal deoxynucleotide transferase-mediated dUTP biotin nick-end labeling (TUNEL) procedure (15) revealed no reactivity in the nontransgenic spleens except for an occasional cell in the red pulp (Fig. $4 h$ ); however, overwhelming reactivity was observed throughout the residual white pulp in the transgenic mice (Fig. $4 j$ ). This suggests that lymphoid depletion in the spleen was the result of accelerated death of $\mathrm{T}$ cells by apoptosis. It should be pointed out that the TUNEL method detects only dying cells with significant DNA fragmentation but not dead cells with already 


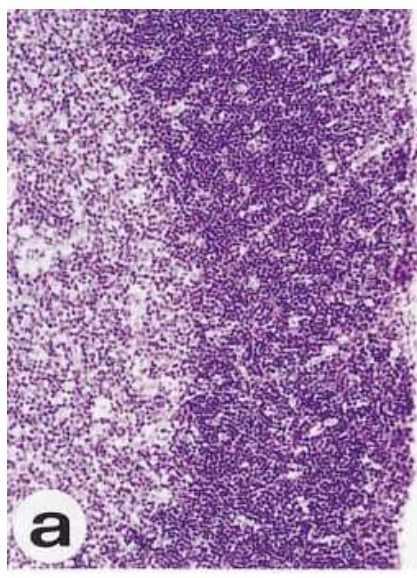

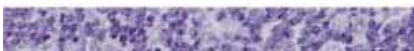
r.tos 5 . e.to

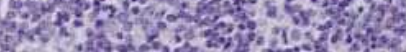
W.

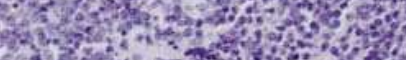
W $207 \%$.

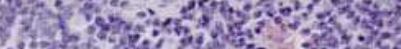

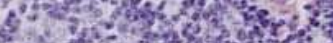

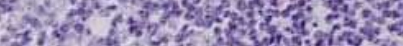

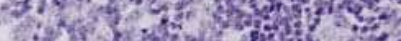

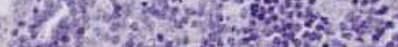

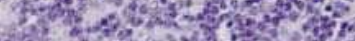
2 S. (e of,

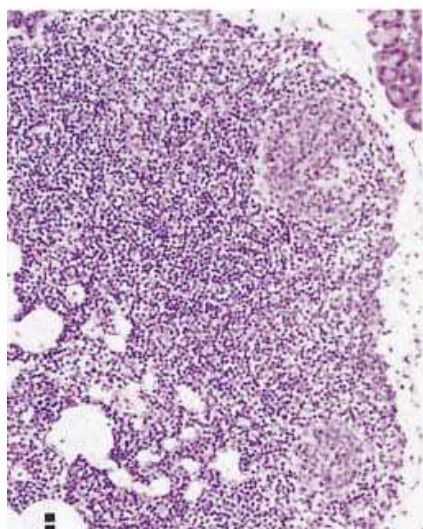
i Wer

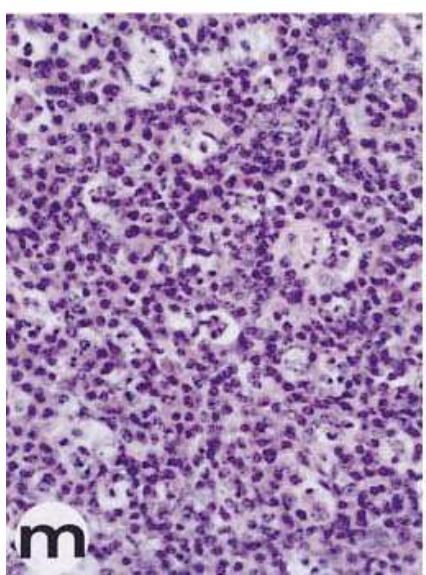

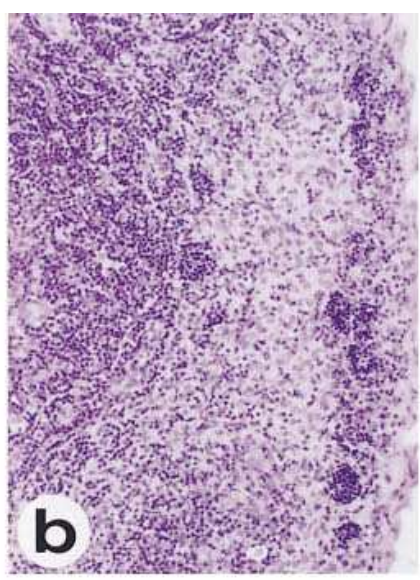
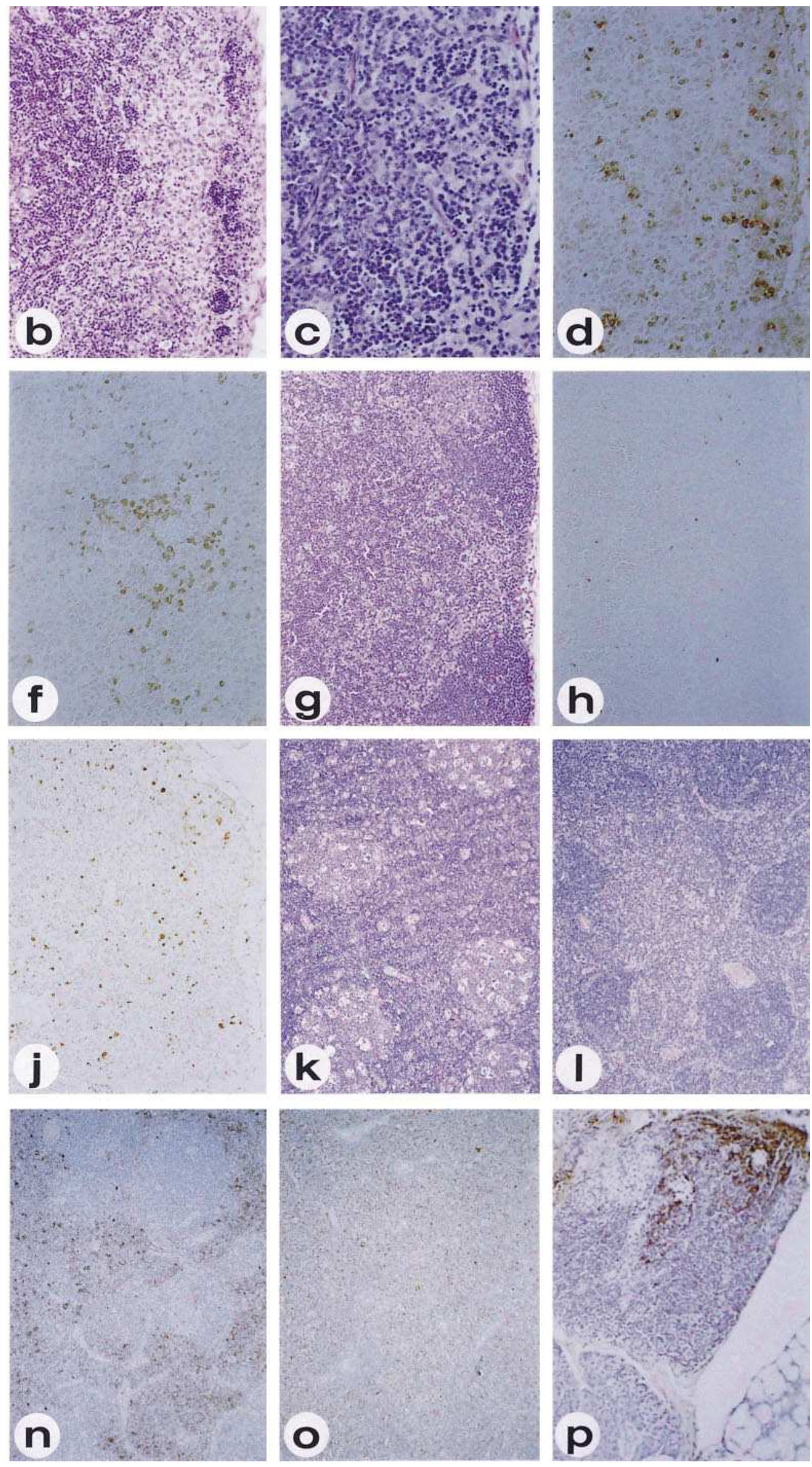
disintegrated nuclei. Given the apparent short time-scale for the apoptotic process, the number of TUNEL-reactive cells we detected suggests an overwhelming wave of cell death in these mice. Cytofluorometric analysis of cells from the spleen at this late stage revealed an abundance of cell debris but virtually no detectable $\mathrm{CD}^{+}$or $\mathrm{CD}^{+}$cells (data not shown), in agreement with the extensive cell death detected by the TUNEL procedure.

Interestingly, the wave of T cell death in the periphery was complete within a matter of days in Q5 mice. On the other hand, depletion occurred progressively over months in N4 mice. In fact, in the latter case, distinct morphologic stages were apparent in different transgenic animals; depletion was found initially within the outer marginal zone which contains resident macrophages with phagocytosed apoptotic bodies (Fig. $4 k$ ), and then proceeded to involve the inner periarteriolar sheath which contained numerous pyknotic cells (Fig. $4 l$ ). The lymphoid depletion in N4 mice eventually progressed and destroyed the entire white pulp area. It is apparent that high levels of HIV gene expression gave rise to acute T cell depletion and early death of Q5 mice, while low level of expression resulted in prolonged $\mathrm{T}$ cell depletion and increased survival of N4 mice.

Lymphoid changes were not restricted to peripheral lymphoid organs but were even more prominent in the thymus. Up to $26 \mathrm{~d}$ of age, the Q5 mice had a fairly normal appearing thymus (Fig. $6 a$ ); thereafter, the cortical region became depleted over a couple of days (Fig. $6 b$ ). Loss of lymphocytes in this region was consistently more rapid and more extensive than in the spleen of the same mouse. Of the remaining cells in the cortical region of thymus (Fig. $6 c$ ), many continued to undergo apoptosis as shown by TUNEL analysis (Fig. $6 d$ ). Cell death in the thymus was not restricted to the cortex but was also detected in the medulla, although not as rapidly or extensively (Fig. $6 e$ ). Unlike in the cortex, apoptotic cells within the medulla appeared in focal areas rather than evenly dispersed throughout the region (Fig. 6, $e$ and $f$ ). This pattern of sequential events within various lymphoid compartments suggests that immature double-positive cells may be more susceptible to HIV-induced apoptosis than mature single-positive cells.

The dropout of T cells was accompanied by functional consequences. A typical lymph node from a nontransgenic mouse showed clear segregation of B and T lymphocytes, with B cells forming discrete primary follicles in the subcapsular region and $\mathrm{T}$ cells occupying the paracortical region (Fig. $6 g$ ). On occasion, an enlarged germinal center (secondary follicle) was detected. TUNEL analysis revealed few apoptotic cells in the normal lymph node, except in the expanded germinal center (Fig. 6 h). In lymph nodes from Q5 mice, not only was the paracortical region somewhat depleted (Fig. $6 i$ ), but many of the remaining cells were undergoing apoptosis (Fig. $6 j$ ). In some lymph nodes, depletion was extensive. This suggests that hypocellularity was due to the death of T cells, rather than to their removal or their lack of replenishment. Significantly, there was complete loss of primary follicles and accentuation of germinal centers (Fig. $6 i$ ). It appeared that depletion of $\mathrm{T}$ cells in the lymph nodes was accompanied by significant alterations in the B cell compartment. This was also observed in the spleen where depleting $\mathrm{T}$ cell areas had several expanded germinal centers (Fig. $4 k$ ).

Activation of the germinal center in lymph nodes was more pronounced in N4 mice where T cell loss was more gradual and the window of time available for such changes was more protracted (Fig. $6 \mathrm{k}$ ). Expanded germinal centers appeared highly reactive, with frequent apoptotic bodies within tingiblebody macrophages. This pattern is highly reminiscent of follicular hyperplasia observed in HIV-infected individuals with early stage persistent generalized lymphadenopathy (16-18). As evidence for germinal center activation giving rise to expansion of the B cell compartment, analysis of lymph nodes from old N4 mice frequently showed surviving T lymphocytes confined into pools on a background of B lymphocytes (Fig. $6 \mathrm{l}$ ). The B cells were predominantly immunoblasts, with a characteristic basophilic cytoplasm and a low mitotic index (Fig. $6 \mathrm{~m}$ ). These cells also seemed to have a significant apoptotic rate, as indicated both by the "starry-sky" tissue morphology and by TUNEL reactivity. That these are B cells was confirmed by immunostaining with an antibody directed against immunoglobulin (Fig. $6 n$ ), which selectively identified the background B cells but not the focal areas of T cells. This finding is consistent with our detection of an increase in circulating levels of IgM in the mice (data not shown). Interestingly, these observations mirror the polyclonal B cell hyperplasia observed in HIV infection (19-21). In particular, the histopathological features in N4 transgenic mice have marked resemblance to AIDS-associated lymphoma $(22,23)$.

Replacement of $\mathrm{T}$ cells by B cells was virtually complete in some N4 mice, where cells in the entire lymph node were $\mathrm{Ig}^{+}$

Figure 6. Histopathological changes in the transgenic thymus and lymph node. (a) H\&E-stained section of a Q5 thymus showing a distinct demarcation between the cortex and the medulla $(\times 20)$. (b) H\&E-stained section of a Q5 thymus showing extensive cortical depletion and blurring of the corticomedullary junction $(\times 20)$. (c) High magnification view of an H\&E-stained section of the cortical region of a Q5 mouse showing residual T lymphocytes in the depleted cortex $(\times 50)$. $(d)$ Serial section of $c$ that has been subjected to TUNEL analysis to reveal scattered apoptotic cells with significant nuclear DNA fragmentation $(\times 50)$. $(e)$ High magnification view of an H\&E-stained section of the medulla from the same Q5 mouse showing clustering of pyknotic cells $(\times 50)$. $(f)$ Serial section of $e$ that has been subjected to TUNEL analysis to show a regional overlap between the pyknotic cells and nuclear DNA fragmentation $(\times 50)$. $(g)$ H\&E-stained section of a lymph node from a nontransgenic mouse, showing the locations of the primary follicles, with an occasional enlarged germinal center, and the paracortical region. $(h)$ Serial section of $g$ stained by TUNEL to show an occasional apoptotic cell in the paracortex. (i) H\&E-stained section of a lymph node from a Q5 mouse, showing both a depleted paracortical region and presence of multiple germinal centers. ( $j$ ) Serial section of $i$ stained by TUNEL to reveal extensive cell death throughout the paracortex. $(k) \mathrm{H} \& \mathrm{E}$-stained section of a lymph node from a N4 mouse, showing numerous germinal center expansions over a background of depleting T cells. $(l)$ H\&E-stained section of a N4 lymph node with the remaining T cells being confined to focal areas over a background of B cells. $(m)$ High magnification view of the B-cell zone in $l$, to show that most cells were immunoblasts. $(n)$ Immunostaining of an $\mathrm{N} 4$ lymph node with focal areas of $\mathrm{Ig}^{-} \mathrm{T}$ cells among a background of $\mathrm{Ig}^{+} \mathrm{B}$ cells. $(o)$ Immunostaining of an $\mathrm{N} 4$ lymph node with virtual complete replacement of $\mathrm{Ig}^{-} \mathrm{T}$ cells with $\mathrm{Ig}^{+} \mathrm{B}$ cells. $(p)$ Immunostaining of depleting Q5 lymph node with $\mathrm{Ig}^{+} \mathrm{B}$ cells intermingling with $\mathrm{Ig}^{-} \mathrm{T}$ cells. 
(Fig. $6 o$ ). Paracortical accumulation of B immunoblasts suggests a lack of proper $T$ cell control and may reflect the lack of signals for further differentiation. The increase in nodal volume gave rise to lymphadenopathy in these mice. In young Q5 mice, where $\mathrm{T}$ cell depletion was significantly more accelerated, expansion of B cells, while not necessarily morphologically apparent, could similarly be detected when lymph nodes were immunostained with anti-Ig (Fig. $6 p$ ). Of importance is the observation that these $\mathrm{B}$ immunoblasts have no detectable HIV gene expression, either by in situ hybridization analysis or by anti-Rev immunostaining. This indicates that the change in the B-cell compartment was secondary to loss of the $\mathrm{T}$ cell compartment in these transgenic mice.

\section{Discussion}

This study has provided several observations implicating HIV in inducing T-cell depletion in mice. $(A)$ Despite abundant HIV gene expression during the first 4 wk of life, both the thymus and the peripheral lymphoid organs appeared normal. This suggests that thymopoiesis itself is not directly affected by HIV and that the bone marrow is an unlikely target. $(B)$ Concomitant with full lymphoid maturation at $\sim 4-5 \mathrm{wk}$ of age, $\mathrm{T}$ cells undergo apoptosis as a consequence of HIV gene expression. This is consistent with the differentiation state of the $\mathrm{T}$ cell playing a role in its susceptibility to HIV killing. $(C)$ Cells in the thymic cortex appear more sensitive than cells in the thymic medulla and peripheral lymphoid organs. Despite this apparent difference, the mechanism underlying the apoptotic process is likely to be shared between the double-positive and the single-positive T cells. (D) The higher the level of HIV gene expression, the more rapid and extensive is depletion of $\mathrm{T}$ cells. This may reflect the difference between acute and chronic responses to HIV infections depending upon the viral load. $(E)$ Although we can conclude that HIV replication is not required for the T-cell depletion and that none of the viral structural proteins (Gag, Pol, or Env) are involved, it is still not clear which HIV nonstructural protein(s) is responsible. $(F)$ Gradual loss of T cells was accompanied by gradual expansion of B immunoblasts which had no detectable viral gene expression. This may explain the origin of the polyclonal B cell lymphomas which are found in AIDS patients. These findings have not been previously observed in transgenic studies involving different HIV genes under either the HIV LTR or a heterologous transcriptional promoter (24-26).

Although there is increasing evidence for HIV driving the killing of $\mathrm{CD}^{+} \mathrm{T}$ cells in infected individuals $(5,6)$, it remains unclear whether the effect is direct (7-9). Many of the suggestions of an indirect mechanism of action of HIV involve gp120 as the determining viral factor. However, our findings suggest that the Env protein is not required for lymphoid depletion in the transgenic mouse model. Although we cannot conclude that HIV gene expression leads directly to the death of the cell, our observations do not rule out an indirect mechanism of killing. The fact that HIV gene expression did not appear sufficient to cause cell death until the mice reached full immune maturation, at which time depletion proceeded precipitously, suggests that the state of maturation of the $\mathrm{T}$ cell is important for susceptibility to killing.

The transgenic approach will hopefully allow us to identify which HIV nonstructural gene(s) is responsible for inducing the lymphoid changes and, more importantly, define the un- derlying mechanism(s) of immune cell dysfunction and death. However, it is possible that multiple HIV genes may be involved in the complex changes that we observed. For example, both tat and nef have the ability to induce apoptosis in tissue culture cells $(25,27)$. Additionally, rev has been shown to induce cytotoxicity (28) and $v p r$ can cause cell cycle arrest (29, 30). All of these in vitro activities may be acting in concert in vivo in the transgenic mouse. Indeed, we have already demonstrated using specific PCR primers that both Tat and Rev transcripts accumulate in the involved lymphoid tissues. It will be important to determine whether the other viral transcripts are also present and whether transgenic mice carrying individual HIV genes will develop similar pathologies.

Apart from the debate on why CD4 cells die in HIV-infected individuals (1-9), it is also not clear how they die. Our demonstration of DNA fragmentation by in situ detection of DNA breaks, together with characteristic morphological features, suggests that cell death in the HIV transgenic mice is by apoptosis. This conclusion is consistent with studies using either cell lines (31-35) or SCID-hu mice (36-38) infected with HIV. The fact that our transgene does not encode the Env protein demonstrates that gp120 is not required for the apoptotic process, in contrast to what has been speculated (39-41). However, it is interesting to note that the Tat protein is implicated in inducing T-cell death (27); our transgenic mice also express the tat gene. We are hopeful that these transgenic mice will facilitate the identification of cellular genes involved in the apoptotic pathway in T cells.

Immune dysfunctions in HIV-infected individuals are exceedingly complex and some of these changes are expected to be secondary to the perturbation of function of $\mathrm{CD}^{+} \mathrm{T}$ cells $(4,42)$. Patients with AIDS have an increase in both circulating immature B cells $(43,44)$ and level of spontaneous immunoglobulin production $(20,21,45)$. B cell disorders may result from maturational arrest at the germinal center stage (46) and may contribute to the development of AIDS-associated lymphoma $(22,23)$. The findings with our HIV transgenic mice are consistent with these changes being indirect consequences of $\mathrm{T}$ cell loss. These mice may be useful for elucidating altered signaling pathways which are responsible for various immune dysfunctions.

In conclusion, our transgenic model is an attempt to define only certain aspects of HIV pathogenesis. Since the chimeric construct cannot support viral replication, events related to the viral life cycle are not addressed. Processes involving free viruses and viral infection are nonexistent. Since the viral gene products expressed in the transgenic mice are likely to have induced immunological tolerance, we have not observed evidence of immune reactivity to viral antigens which are known to occur in HIV-infected patients. As a result, our transgenic studies address only a subset of events which occur in natural HIV infection of humans. In particular, events which are related to the intracellular accumulation of viral gene products may be exaggerated in a setting where other events do not occur. This may facilitate molecular dissection of the underlying mechanism of involvement, in the absence of adjunct activities occurring simultaneously.

\section{Acknowledgments}

We thank Ms. Lisa Ruiz for her help in the preparation of the manuscript. 
This work was supported by U.S. Public Health Service grant CA53633 to Dr. G. Jay.

\section{References}

1. Gallo, R.C., and L. Montagnier. 1988. AIDS in 1988. Sci. Am. 259:40-48.

2. Fauci, A.S. 1993. Multifactorial nature of human immunodeficiency virus disease: implications for therapy. Science (Wash. DC). 262:1011-1018.

3. Weiss, R.A. 1993. How does HIV cause AIDS? Science (Wash. DC). 260 : 1273-1279.

4. Levy, J.A. 1993. Pathogenesis of human immunodeficiency virus infection. Microbiol. Rev. 57:183-289.

5. Wei, X., S.K. Ghosh, M.E. Taylor, V.A. Johnson, E.A. Emini, P. Deutsch, J.D. Lifson, S. Bonhoeffer, M.A. Nowak, B.H. Hahn, et al. 1995. Viral dynamics in human immunodeficiency virus type 1 infection. Nature (Lond.). 373:117122

6. Ho, D.D., A.U. Neumann, A.S. Perelson, W. Chen, J.M. Leonard, and M. Markowitz. 1995. Rapid turnover of plasma virions and CD4 lymphocytes in HIV-1 infection. Nature (Lond.). 373:123-129.

7. Finkel, T.H., G. Tudor-Williams, N.K. Banda, M.F. Cotton, T. Curiel, C. Monks, T.W. Baba, R.M. Ruprecht, and A. Kupfer. 1995. Apoptosis occurs predominantly in bystander cells and not in productively infected cells of HIV-and SIV-infected lymph nodes. Nat. Med. 1:129-134.

8. Ascher, M.S., H.W. Sheppard, J.F. Krowka, and H.J. Bremermann. 1995. AIDS as immune system activation: key questions that remain. Adv. Exp. Med. Biol. 374:203-210.

9. Roederer, M., J.G. Dubs, M.T. Anderson, P.A. Raju, L.A. Herzenberg, and L.A. Herzenberg. 1995. CD8 naive T cell counts decrease progressively in HIV-infected adults. J. Clin. Invest. 95:2061-2066.

10. Klotman, M.E., and F. Wong-Staal. 1991. Human immunodeficiency virus (HIV) gene structure and genetic diversity. In The Human Retroviruses. R.C. Gallo and G. Jay, editors. Academic Press, San Diego. 35-67.

11. Haseltine, W.A. 1991. Human immunodeficiency virus (HIV) gene expression and function. In The Human Retroviruses. R.C. Gallo and G. Jay, editors. Academic Press, New York. 69-106.

12. Levy, J.A., A.D. Hoffman, S.M. Kramer, J.A. Landis, and J.M. Shimabukuro. 1984. Isolation of lymphocytopathic retroviruses from San Francisco patients with AIDS. Science (Wash. DC). 225:840-842.

13. Schwartz, S., B.K. Felber, D.M. Benko, E.-M. Fenyö, and G.N. Pavlakis. 1990. Cloning and functional analysis of multiply spliced mRNA species of human immunodeficiency virus type 1. J. Virol. 64:2519-2529.

14. Cochrane, A.W., A. Perkins, and C.A. Rosen. 1990. Identification of sequences important in the nucleolar localization of human immunodeficiency virus Rev: relevance of nucleolar localization to function. J. Virol. 64:881-885.

15. Gavrieli, Y., Y. Sherman, and S.A. Ben-Sasson. 1992. Identification of programmed cell death in situ via specific labeling of nuclear DNA fragmentation. J. Cell Biol. 119:493-501.

16. Ioachim, H.L., C.W. Lerner, and M.L. Tapper. 1983. Lymphadenopathies in homosexual men: relationships with the acquired immune deficiency syndrome. J. Am. Med. Assoc. 250:1306-1309.

17. Burns, B.F., G.S. Wood, and R.F. Dorfman. 1985. The varied histopathology of lymphadenopathy in the homosexual male. Am. J. Surg. Pathol. 9: 287-297.

18. Diebold, J., J. Audouin, A. Le Tourneau, S. Prevot, and G. Szekeres. 1990. Lymph node reaction patterns in patients with AIDS or AIDS-related complex. Curr. Top. Pathol. 84:189-221.

19. O'Hara, C.J. 1989. The lymphoid and hematopoietic systems. In Pathology and Pathophysiology of AIDS and HIV-related Diseases. S.J. Harawi and C.J. O'Hara, editors. The C.V. Mosby Co., Washington, DC. 135-199.

20. Amadori, A., and L. Chieco-Bianchi. 1990. B-cell activation and HIV-1 infection: deeds and misdeeds. Immunol. Today. 11:374-379.

21. Shirai, A., M. Cosentino, S.F. Leitman-Klinman, and D.M. Klinman. 1992. Human immunodeficiency virus infection induces both polyclonal and virus-specific B cell activation J. Clin. Invest. 89:561-566.

22. McGrath, M.S., B. Shiramizu, T.C. Meeker, L.D. Kaplan, and B. Herndier. 1991. AIDS-associated polyclonal lymphoma: identification of a new HIV-associated disease process. J. Acquired Immune Defic. Syndr. Hum. Retrovirol. 4:408-415.

23. Knowles, D.M., and R. Dalla-Favera. 1993. AIDS-associated malignant lymphoma. In Textbook of AIDS Medicine. S. Broder, T.C. Merigan, Jr., and D. Bolognesi, editors. Williams \& Wilkins, Baltimore, MD. 431-463.

24. Abramczuk, J.W., D.S. Pezen, J.M Leonard, E. Monell-Torrens, J.H. Belcher, M.A. Martin, and A.L. Notkins. 1992. Transgenic mice carrying intact HIV provirus: biological effects and organization of a transgene. J. Acquired Immune Defic. Syndr. 5:196-203.

25. Skowronski, J., D. Parks, and R. Mariani. 1993. Altered T cell activation and development in transgenic mice expressing the HIV-1 nef gene. EMBO (Eur. Mol. Biol. Organ.) J. 12:703-713.
26. Vellutini, C., N. Horschowski, V. Philippon, D. Gambarelli, K.-A. Nave, and P. Filippi. 1995. Development of lymphoid hyperplasia in transgenic mice expressing the HIV tat gene. AIDS Res. Hum. Retroviruses. 11:21-29.

27. Li, C.J., D.J. Friedman, C. Wang, V. Metelev, and A.B. Pardee. 1995. Induction of apoptosis in uninfected lymphocytes by HIV-1 Tat protein. Science (Wash. DC). 268:429-431.

28. Miyazaki, Y., T. Takamatsu, T. Nosaka, S. Fujita, T.E. Martin, and M. Hatanaka. 1995. The cytotoxicity of human immunodeficiency virus type $1 \mathrm{Rev}$ implications for its interaction with the nucleolar protein B23. Exp. Cell. Res. 219:93-101.

29. Rogel, M.E., L.I. Wu, and M. Emerman. 1995. The human immunodeficiency virus type $1 \mathrm{vpr}$ gene prevents cell proliferation during chronic infection. J. Virol. 69:882-888.

30. Jowett, J.B., V. Planelles, B. Poon, N.P. Shah, M.L. Chen, and I.S. Chen. 1995. The human immunodeficiency virus type $1 \mathrm{vpr}$ gene arrests infected $\mathrm{T}$ cells in the G2 + M phase of the cell cycle. J. Virol. 69:6304-6313.

31. Laurent-Crawford, A.G., B. Krust, S. Muller, Y. Riviere, M.-A. ReyCuillé, J.-M. Béchet, L. Montagnier, and A.G. Hovanessian. 1991. The cytopathic effect of HIV is associated with apoptosis. Virology. 185:829-839.

32. Meyaard, L., S.A. Otto, R.R. Jonker, M.J. Mijnster, R.P. Keet, and F. Miedema. 1992. Programmed death of T cells in HIV-1 infection. Science (Wash. DC). 257:217-219.

33. Sandstrom, P.A., B. Roberts, T.M. Folks, and T.M. Buttke. 1993. HIV gene expression enhances $\mathrm{T}$ cell susceptibility to hydrogen peroxide-induced apoptosis. AIDS Res. Hum. Retroviruses. 9:1107-1113.

34. Estaquier, J., T. Idziorek, F. deBels, F. Barré-Sinoussi, B. Hurtrel, A.-M. Aubertin, A. Venet, M. Mehtali, E. Muchmore, P. Michel, et al. 1994 Programmed cell death and AIDS: significance of T-cell apoptosis in pathogenic and nonpathogenic primate lentiviral infections. Proc. Natl. Acad. Sci. USA. 91:9431-9435.

35. Maldarelli, F., H. Sato, E. Berthold, J. Orenstein, and M.A. Martin 1995. Rapid induction of apoptosis by cell-to-cell transmission of human immunodeficiency virus type 1. J. Virol. 69:6457-6465.

36. Bonyhadi, M.L., L. Rabin, S. Salimi, D.A. Brown, J. Kosek, J.M. McCune, and H. Kaneshima. 1993. HIV induces thymus depletion in vivo. Nature (Lond.). 363:728-732.

37. Aldrovandi, G.M., G. Feuer, L. Gao, B. Jamieson, M. Kristeva, I.S.Y Chen, and J.A. Zack. 1993. The SCID-hu mouse as a model for HIV-1 infection. Nature (Lond.). 363:732-736.

38. Stanley, S.K., J.M. McCune, H. Kaneshima, J.S. Justement, M. Sullivan, E. Boone, M. Baseler, J. Adelsberger, M. Bonyhadi, J. Orenstein, et al. 1993. Human immunodeficiency virus infection of the human thymus and disruption of the thymic microenvironment in the SCID-hu mouse. J. Exp. Med. 178:11511163

39. Banda, N.K., J. Bernier, D.K. Kurahara, R. Kurrle, N. Haigwood, R.P Sekaly, and T.H. Finkel. 1992. Crosslinking CD4 by human immunodeficiency virus gp120 primes T cells for activation-induced apoptosis. J. Exp. Med. 176: 1099-1106.

40. Laurent-Crawford, A.G., B. Krust, Y. Riviere, C. Desgranges, S. Muller, M.P. Kieny, C. Dauguet, and A.G. Hovanessian. 1993. Membrane expression of HIV envelope glycoproteins triggers apoptosis in CD4 cells. AIDS Res. Hum. Retroviruses. 9:761-773.

41. Gougeon, M.L., A.G. Laurent-Crawford, A.G. Hovanessian, and L. Montagnier. 1993. Direct and indirect mechanisms mediating apoptosis during HIV infection: contribution to in vivo CD4 T cell depletion. Semin. Immunol. 5: 187-194.

42. Emilie, D., R. Fior, L. Llorente, A. Marfaing-Koka, M. Peuchmaur, O. Devergne, B. Jarrousse, J. Wijdenes, F. Boue, and P. Galanaud. 1994. Cytokines from lymphoid organs of HIV-infected patients: production and role in the immune disequilibrium of the disease and in the development of B lymphomas. Immunol. Rev. 140:5-34.

43. Martinez-Maza, O., E. Crabb, R.T. Mitsuyasu, J.L. Fahey, and J.V. Giorgi. 1987. Infection with the human immunodeficiency virus (HIV) is associated with an in vivo increase in B lymphocyte activation and immaturity. J. Immunol. 138:3720-3724.

44. Reddy, M.M., R.R. Goetz, J.M. Gorman, M.H. Grieco, L. Chess, and S. Lederman. 1991. Human immunodeficiency virus type-1 infection of homosexual men is accompanied by a decrease in circulating B cells. J. Acquired Immune Defic. Syndr. 4:428-434.

45. Papadopoulos, N.M., H.C. Lane, R. Costello, H.M. Moutsopoulos, H. Masur, E.P. Gelmann, and A.S. Fauci. 1985. Oligoclonal immunoglobulins in patients with the acquired immunodeficiency syndrome. Clin. Immunol. Immunopathol. 35:43-46.

46. Berberian, L., Y. Valles-Ayoub, N. Sun, O. Martinez-Maza, and J. Braun. 1991. A VH clonal deficit in human immunodeficiency virus-positive individuals reflects a B-cell maturational arrest. Blood. 78:175-179.

47. Sanchez-Pescador, R., M.D. Power, P.J. Barr, K.S. Steimer, M.M Stampien, S.L. Brown-Shimer, W.W. Gee, A. Renard, A. Randolph, J.A. Levy, et al. 1985. Nucleotide sequence and expression of an AIDS-associated retrovirus (ARV-2). Science (Wash. DC). 227:484-492. 